DOI: 10.1002/ ((please add manuscript number))

Article type: Full Paper

\title{
Biosynthesis and Characterization of Copper Nanoparticles Using Shewanella oneidensis: Application for Click Chemistry
}

Richard L. Kimber*, Edward A. Lewis, Fabio Parmeggiani, Kurt Smith, Heath Bagshaw, Toby Starborg, Nimisha Joshi, Adriana I. Figueroa, Gerrit van der Laan, Giannantonio Cibin, Diego Gianolio, Sarah J. Haigh, Richard A.D. Pattrick, Nicholas J. Turner, Jonathan R. Lloyd

Dr. R.L. Kimber, Dr. K. Smith, Dr. H. Bagshaw, Dr. N. Joshi, Prof. R.A.D. Pattrick, Prof. J.R. Lloyd

School of Earth and Environmental Sciences and Williamson Research Centre for Molecular Environmental Science, University of Manchester, Manchester, UK

*E-mail: Richard.kimber@ manchester.ac.uk

Dr. E.A. Lewis, Dr. S.J. Haigh

School of Materials, University of Manchester, Manchester, UK

Dr. F. Parmeggiani, Prof. N. Turner

School of Chemistry, Manchester Institute of Biotechnology, University of Manchester, Manchester, UK

Dr. T. Starborg

Wellcome Centre for Cell Matrix Research, University of Manchester, Manchester, UK

Dr. A.I. Figueroa, Prof. G. van der Laan

Magnetic Spectroscopy Group, Diamond Light Source, Didcot, Oxfordshire, UK

Dr. G. Cibin, Dr. D. Gianolio

Diamond Light Source, Didcot, Oxfordshire, UK

Keywords: copper nanoparticles; biosynthesis; click chemistry; Shewanella oneidensis; XANES 


\section{Abstract}

Copper nanoparticles (Cu-NPs) have a wide range of applications as heterogeneous catalysts. Here, we demonstrate a novel green biosynthesis route for producing $\mathrm{Cu}-\mathrm{NPs}$ using the metal-reducing bacterium, Shewanella oneidensis. Thin section transmission electron microscopy (TEM) shows that the Cu-NPs are predominantly intracellular and present in a typical size range of $20-40 \mathrm{~nm}$. Serial block-face scanning electron microscopy (SBFSEM) demonstrates the Cu-NPs are well-dispersed across the three dimensional (3D) structure of the cells. X-ray absorption near-edge spectroscopy (XANES) and extended x-ray absorption fine-structure spectroscopy (EXAFS) analysis shows the nanoparticles are $\mathrm{Cu}(0)$, however, atomic resolution images and electron energy loss spectroscopy (EELS) suggest partial oxidation of the surface layer to $\mathrm{Cu}_{2} \mathrm{O}$ upon exposure to air. The catalytic activity of the $\mathrm{Cu}$ NPs is demonstrated in an archetypal 'click chemistry' reaction, generating good yields during azide-alkyne cycloadditions ( $\mathrm{CuAAC})$, most likely catalyzed by the $\mathrm{Cu}(\mathrm{I})$ surface layer of the nanoparticles. Furthermore, cytochrome deletion mutants suggest a novel metal reduction system is involved enzymatic $\mathrm{Cu}(\mathrm{II})$ reduction, and $\mathrm{Cu}-\mathrm{NP}$ synthesis, which is not dependent on the Mtr pathway commonly used to reduce other high oxidation state metals in this bacterium. This work demonstrates a simple, green synthesis method for producing efficient copper nanoparticle catalysts.

\section{Introduction}

Due to its high natural abundance and relatively low cost, copper has attracted considerable attention as a viable alternative to more traditional rare and expensive precious metal catalysts. Copper nanoparticles (Cu-NPs) have a wide range of applications in organic transformations, gas-phase catalysis, photocatalysis, and electrocatalysis. ${ }^{1}$ Particularly, 
copper catalysis has attracted significant interest since the discovery that the Huisgen 1,3dipolar cycloaddition reaction of azides with terminal alkynes can be greatly accelerated in the presence of copper(I) under mild conditions, combined with high regioselectivity toward the 1,4-disubstituted 1,2,3-triazole..$^{2-3}$ Copper-catalyzed azide-alkyne cycloaddition (CuAAC) is an archetypal 'click chemistry' reaction and has a wide range of applications in drug discovery, ${ }^{4-6}$ bioconjugation, ${ }^{7-9}$ and materials science. ${ }^{8,10}$

Nanoparticles make excellent catalysts due to their high surface area and increased number of defect sites relative to polycrystalline materials. ${ }^{11-12}$ Furthermore, the use of heterogeneous catalysts such as Cu-NPs offers advantages in increased reusability and efficiency, compared to their homogeneous counterparts. ${ }^{13-14}$ Microbial metabolism can be harnessed to offer potentially simple, inexpensive, environmentally benign processes for nanocatalyst production. ${ }^{15}$ Proteins and other biomolecules involved in the microbial process can act as capping agents, enhancing nanoparticle stability and limiting aggregation, thus preventing the need for chemical capping agents or surfactants. ${ }^{16}$ In addition, the process can be scaled-up and controlled to produce nanoparticles with highly tuned properties. ${ }^{17-18}$

Shewanella oneidensis is one of the most versatile and well-studied species of metalreducing bacteria, able to reduce a wide range of metals under anaerobic conditions via direct electron transfer linked to respiratory processes, ${ }^{19}$ precipitating extracellular or intracellular metallic nanoparticles such as $\mathrm{U}, \mathrm{Se}, \mathrm{Pd}, \mathrm{Au}$, and Ag. ${ }^{15,20-23}$ However, to our knowledge, there have been no studies on the synthesis of Cu-NPs by metal-reducing bacteria, including Shewanella species. Microbial synthesis of extracellular $\mathrm{Cu}-\mathrm{NPs}$ was shown to be facilitated by the $\mathrm{Cu}$-resistant intestinal commensal bacterium, Morganella morganii, by Ramanathan et al. ${ }^{24}$ but the reduction methods in this organism remain poorly understood and only limited 
characterization of the $\mathrm{Cu}-\mathrm{NPs}$ was performed. Furthermore, the catalytic activity of $\mathrm{Cu}-\mathrm{NPs}$ synthesized by any microbial process remains to be tested.

This is the first study to investigate bioreduction of $\mathrm{Cu}$ (II) and synthesis of $\mathrm{Cu}-\mathrm{NPs}$ using anaerobic metal-reducing bacteria, which are known to have potential for the production of a wide range of catalytically active metallic nanoparticles. ${ }^{15}$ S. oneidensis MR-1 was selected for study given the broad range of metals that it can reduce, and the availability of deletion mutants that can provide insights into the potential mechanisms of electron transfer to $\mathrm{Cu}(\mathrm{II})$, and the formation of reduced $\mathrm{Cu}-\mathrm{NPs}$. The $\mathrm{Cu}-\mathrm{NPs}$ produced by this organism were characterized using a wide range of analytical techniques including transmission electron microscopy (TEM), X-ray absorption near-edge spectroscopy (XANES), extended X-ray absorption fine-structure spectroscopy (EXAFS), electron energy loss spectroscopy (EELS) and a novel technique for three dimensional (3D) imaging of biomass supported nanoparticles, serial block-face scanning electron microscopy (SBFSEM). Finally, the catalytic potential of biogenic $\mathrm{Cu}-\mathrm{NPs}$ formed by $\mathrm{S}$. oneidensis was demonstrated for the synthesis of a series of 1,2,3-triazole derivatives through the azide-alkyne cycloadditions.

\section{Results and Discussion}

\subsection{Formation and characterization of $\mathrm{Cu}-\mathrm{NPs}$}

To produce biogenic $\mathrm{Cu}-\mathrm{NPs}$, washed cells of the metal-reducing bacterium S. oneidensis MR1 wild type were supplied with $50 \mu \mathrm{M} \mathrm{Cu}(\mathrm{II})$ ions $\left(\mathrm{CuSO}_{4}\right)$ and $30 \mathrm{mM}$ lactate as the electron donor. After 3 hours, $70 \%$ of $\mathrm{Cu}$ was removed from solution (Figure S1), concurrent with a color change of the solution from colorless to pink indicating bioreduction of $\mathrm{Cu}(\mathrm{II})$. After 24 hours, $91 \%$ removal of $\mathrm{Cu}$ from solution was observed followed by complete removal (100\%) after 96 hours (data not shown). Whole mount TEM images revealed that 
$\mathrm{Cu}$ (II) bioreduction resulted in the formation of Cu-NPs (Figure S2). TEM images of thin sections of the cells showed the majority of the Cu-NPs were precipitated intracellularly, although precipitates can also be seen in the extracellular matrix, sometimes forming larger agglomerates associated with the outer membrane of the cells (Figure 1a-d). Energy dispersive X-ray (EDX) point analysis performed during TEM imaging (Figure S3) and EDX spectrum imaging performed in the scanning transmission electron microscope (STEM) (Figure 1f) confirms the electron dense precipitates observed in the thin sections are $\mathrm{Cu}$ rich. The intracellular precipitates were found within both the periplasm and cytoplasm, as shown in Figure 1. Analysis of the size distribution of the nanoparticles, based on measurements of 80 randomly selected particles, shows the majority (88\%) are present in the range of $20-50$ nm (Figure S4). A small number (5\%) of larger aggregates above $200 \mathrm{~nm}$ are also present. As can be seen in Figure 1, the majority of the smaller particles are intracellular whereas the larger agglomerates tend to be associated with the outer membrane of the cells.

The location of the $\mathrm{Cu}-\mathrm{NPs}$ was further determined using a novel technique for imaging biomass supported nanoparticles; serial block-face scanning electron microscopy (SBFSEM). The dispersion of the Cu-NPs on the 3D structure of individual cells is shown (Figure 2). The 3D electron images, combined with the TEM-EDX and STEM-EDX data from the same sample, confirm that the $\mathrm{Cu}-\mathrm{NPs}$ are predominately intracellular and that these precipitates typical fall within the smaller $(20-50 \mathrm{~nm})$ size range (Figure 2). These images also confirm the larger particles, generally larger than $50 \mathrm{~nm}$, are located in the extracellular matrix. The dispersion of NPs is an important factor affecting their catalytic activity and the 3D electron images also clearly show the $\mathrm{Cu}-\mathrm{NPs}$ are very well dispersed across the cell structure, which acts as the support matrix for the NPs. In addition, the spherical 3D shape of the Cu-NPs can be seen clearly as well as the volume fraction of the nanoparticles on the biomass support. 
This highlights the ability of S. oneidensis to both synthesis and support Cu-NPs under environmentally benign conditions without the need of chemical reductants or treatments.

X-ray absorption near edge spectroscopy (XANES) of the Cu-NPs was carried out at the Diamond Light Source to characterize the valence and local structure of the nanoparticles. XANES collected at the $\mathrm{Cu} K$-edge of the $\mathrm{Cu}$-NPs had an absorption edge located at 8979.3 $\mathrm{eV}$. The absorption edges of the $\mathrm{Cu}$ foil, $\mathrm{Cu}_{2} \mathrm{O}$, and $\mathrm{CuO}$ references were located at 8979.3, 8980.6, and $8983.7 \mathrm{eV}$, respectively. The excellent match between the spectra for $\mathrm{Cu}$ foil and the $\mathrm{Cu}$-NPs clearly demonstrates that the bioreduction process involved reduction of $\mathrm{Cu}$ (II) to $\mathrm{Cu}(0)$ (Figure 3a). When collected at the $\mathrm{Cu} L_{2,3}$-edges, XANES spectra from the Cu-NPs also showed an excellent match to the $\mathrm{Cu}$ foil reference (Figure 3b), providing further evidence of the bioreduction of $\mathrm{Cu}$ (II) to $\mathrm{Cu}(0)$. No peaks suggestive of oxidation to $\mathrm{Cu}(\mathrm{I})$ or $\mathrm{Cu}$ (II) were observed at either the $\mathrm{Cu} K$-edge or $\mathrm{Cu} L_{2,3}$-edges. In contrast, spectra collected at the $\mathrm{Cu} L_{2,3}$-edges from commercial $\mathrm{Cu}(0)$ particles showed a peak at $\sim 931 \mathrm{eV}$, indicative of $\mathrm{Cu}(\mathrm{II})$ and a strong peak at $\sim 933 \mathrm{eV}$, indicative of $\mathrm{Cu}(\mathrm{I})$, suggesting the biogenic $\mathrm{Cu}-\mathrm{NPs}$ are more stable against oxidation than commercially available $\mathrm{Cu}(0)$ particles, possibly due to the presence of capping proteins/peptides associated with bacterially produced nanoparticles. ${ }^{16}$

Given the data obtained from the XANES analysis, EXAFS data were fit assuming a similar coordination environment as cubic $\mathrm{Cu}(0)$ (Figure $3 \mathrm{c}, \mathrm{d}) .{ }^{25}$ The best fit was obtained with $\mathrm{Cu}$ coordinated by $9.6 \mathrm{Cu}$ atoms at $2.54 \pm 0.02 \AA ; 6 \mathrm{Cu}$ atoms at $3.57 \pm 0.04 \AA$; $24 \mathrm{Cu}$ atoms at $4.45 \pm 0.03 \AA$; and $9 \mathrm{Cu}$ atoms at $5.29 \pm 0.18 \AA$. See Table $\mathrm{S} 1$ for complete details of fit. The fit was broadly consistent with the reference structure. However, 9.6 and $9 \mathrm{Cu}$ atoms were determined to be coordinated at 2.54 and $5.29 \AA$, respectively; slightly lower than noted in the ideal structure of $12 \mathrm{Cu}$ atoms in both shells. It is possible that this reduced coordination is caused by the nanoparticulate nature of the materials in this study. ${ }^{26}$ 
Atomic resolution imaging of the nanoparticle agglomerates further supports the XAS data that the $\mathrm{Cu}-\mathrm{NPs}$ exist predominantly as metallic $\mathrm{Cu}$ (Figure 4a,b). However, lattice fringes measured from atomic resolution images of some of the smallest particles $\leq 10 \mathrm{~nm}$, are consistent with $\mathrm{Cu}_{2} \mathrm{O}$ (Figure 4c). EELS performed on the interior of the particles shows $\mathrm{Cu}$ L2,3-edge features which match the reference spectrum for $\mathrm{Cu}(0)$ (Figure 5). However, EELS spectra taken at the edge region of the same particle matches closely with the reference spectrum of $\mathrm{Cu}_{2} \mathrm{O}$. It should be noted that the samples were briefly exposed to air during their transfer into the TEM. Taking together the XAS and EELS data suggests the Cu-NPs are predominantly $\mathrm{Cu}(0)$. However, a thin $\mathrm{Cu}_{2} \mathrm{O}$ shell may develop at the surface layer of the particles upon exposure to air, while the core of the particles remain stable as $\mathrm{Cu}(0)$. Mansour et al. also observed the formation of a $\mathrm{Cu}_{2} \mathrm{O}$ shell around chemically synthesized $\mathrm{Cu}(0)$ nanoparticles under an oxygen atmosphere. ${ }^{27}$

\subsection{Application in the $\mathrm{Cu}(\mathrm{I})$-catalyzed azide-alkyne cycloaddition}

To test the catalytic activity of the $\mathrm{Cu}-\mathrm{NPs}$, we investigated the synthesis of a range of triazole derivatives via the $\mathrm{Cu}(\mathrm{I})$-catalysed cycloaddition of benzyl azide (1), with a representative panel of alkynes (2a-c) (Scheme 1). Under mild reaction conditions, with no further processing of the biogenic $\mathrm{Cu}-\mathrm{NPs}$, complete conversions (as monitored by ${ }^{1} \mathrm{H} \mathrm{NMR}$ ) were obtained using a relatively low catalyst loading of $1.1 \mathrm{~mol} \%$. As expected, all reactions showed complete regioselectivity towards 1,4-disubstituted triazoles. Although $\mathrm{Cu}(0)$ has been used to carry out $\mathrm{CuAAC},{ }^{28}$ the reaction is accepted to be catalyzed by $\mathrm{Cu}(\mathrm{I})$ species at the nanoparticle surface. ${ }^{29-30}$ Our XANES and EXAFS analysis indicate the formation of $\mathrm{Cu}(0)$ nanoparticles, however, atomic resolution images and EELS analysis suggest a thin $\mathrm{Cu}_{2} \mathrm{O}$ shell is present after exposure to air and hence, this $\mathrm{Cu}(\mathrm{I})$ surface layer is likely 
responsible for the CuAAC activity of the biosynthesized nanoparticles. The inherent nature of nanoparticles to agglomerate and oxidize further often requires inorganic supports or stabilizing agents to maintain good catalytic activity. ${ }^{31}$ Here, no additional supporting or stabilizing agents were required and no steps were taken to separate the nanoparticles from the biomass demonstrating a simple, green, and effective method for producing catalytically active $\mathrm{Cu}-\mathrm{NPs}$. Although good yields (51-79\%) were reported here, further work to optimize the system is important, for example, to determine optimal reaction times and $\mathrm{Cu}-\mathrm{NP}$ catalyst loading to improve yields.

\subsection{Mechanistic insights into $\mathrm{Cu}(\mathrm{II})$ bioreduction and nanoparticle formation}

In order to develop the mechanistic understanding of $\mathrm{Cu}-\mathrm{NP}$ biosynthesis by $\mathrm{S}$. oneidensis, we compared $\mathrm{Cu}(\mathrm{II})$ bioreduction using the wild type strain and two deletion mutants. Metal reduction in $S$. oneidensis, and in other metal-reducing bacteria, is often facilitated by a network of periplasmic and/or outer membrane c-type cytochromes (heme-containing proteins), which act as terminal reductases for the metals during anaerobic respiration. The Mtr pathway, an electron transport chain containing a series of $c$-type cytochromes which transfer electrons from the cytoplasm to the outer membrane, is one of the key pathways for metal reduction in $S$. oneidensis and has been shown to play an important role in the reduction of poorly soluble Fe(III)- and Mn(IV)- minerals ${ }^{32-34}$ as well as soluble U(VI), ${ }^{20}$ $\mathrm{Tc}(\mathrm{VII}),{ }^{35}$ and $\mathrm{V}(\mathrm{V}) .{ }^{36}$ To identify the importance of various $c$-type cytochromes in $\mathrm{Cu}(\mathrm{II})$ bioreduction and $\mathrm{Cu}-\mathrm{NP}$ formation, bioreduction was compared using $S$. oneidensis $\mathrm{MR}-1$ wild type cells with those of two cytochrome deletion mutants, JG596 and JG1453.

Deletion of the outer membrane $c$-type cytochromes MtrC, MtrF and OmcA (JG596) and the outer membrane and periplasmic cytochromes MtrABCDEF, OmcA, DmsE, S04360, 
CctA (JG1453) had little effect on the rate or extent of $\mathrm{Cu}(\mathrm{II})$ reduction. When supplied with $50 \mu \mathrm{M} \mathrm{Cu}(\mathrm{II})$, the two mutant strains reduced $82-89 \%$ of $\mathrm{Cu}(\mathrm{II})$ over 24 hours, compared to the $91 \%$ reduced by the wild type (Figure S1). All strains reduced $100 \% \mathrm{Cu}(\mathrm{II})$ after 72 hours. When $200 \mu \mathrm{M} \mathrm{Cu}(\mathrm{II})$ was used, all 3 strains reduced between 26 and $32 \%$ of the $\mathrm{Cu}$ after 24 hours (Figure S1). Autoclaved cell controls showed no decrease in $\mathrm{Cu}(\mathrm{II})$ solution concentrations (Figure $\mathrm{S} 1$ ) suggesting that $\mathrm{Cu}$ (II) removal was facilitated predominately by active $\mathrm{Cu}$ uptake and/or bioreduction by metabolically active cells, rather than by passive biosorption to the cell biomass. Cell free controls containing the electron donor lactate also showed no $\mathrm{Cu}(\mathrm{II})$ removal (Figure $\mathrm{S} 1$ ), consistent with enzymatic "bioreduction" mechanisms. The morphology and localization of the $\mathrm{Cu}$-NPs produced by the deletion mutants was similar to that seen in the wild type, with small $(20-40 \mathrm{~nm})$ individual particles being the most dominant and some larger agglomerates also present. The similarity in both extent and rate of reduction between the wild type and mutants suggests that $\mathrm{Cu}(\mathrm{II})$ reduction is not facilitated by direct contact with $c$-type cytochromes in the Mtr pathway (beyond the cytoplasmic membrane-bound cytochrome CymA).The similarity in $\mathrm{Cu}-\mathrm{NP}$ precipitation and morphology between the wild type and deletion mutants further supports this.

Deletion of MtrC and OmcA has also been shown to have little impact on the reduction of Pd(II) and Se(IV). ${ }^{37-38}$ Deletion of hydA which encodes the [NiFe]-hydrogenase HyaB significantly slowed the bioreduction of $\mathrm{Pd}(\mathrm{II})$, whereas a mutant lacking the fumarate reductase FccA showed significantly decreased Se(IV) reduction capability. NADH dehydrogenase-2 (NDH-2) was shown to promote $\mathrm{Cu}(\mathrm{II})$ reduction to $\mathrm{Cu}(\mathrm{I})$ under aerobic conditions in Escherichia coli. ${ }^{39} \mathrm{NDH}-2$ is present as a cytoplasmic membrane-bound enzyme, upstream of $\mathrm{CymA}$, in $S$. oneidensis and so may play a role in $\mathrm{Cu}$ (II) reduction coupled to NADH oxidation. Therefore, the diverse electron transport pathways in $S$. 
oneidensis present a wide range of possible mechanisms outside of the Mtr pathway, which could facilitate $\mathrm{Cu}$ (II) reduction. Further work is required to identify the specific reductase(s) responsible.

The observation of substantial cytoplasmic $\mathrm{Cu}-\mathrm{NP}$ precipitation (Figures 1 and 2) is surprising as for most bacteria, copper-requiring enzymes are located either within the periplasm or embedded in the cytoplasmic membrane, and so there are no known metabolic requirements for copper to enter the cytosol. ${ }^{40}$ Hence, a variety of $\mathrm{Cu}$ defence mechanisms, including cytoplasmic $\mathrm{Cu}$ exporters, ${ }^{41}$ tightly control $\mathrm{Cu}$ homeostasis in Gram-negative bacteria including $S$. oneidensis. We suggest several mechanisms which may be responsible for the extent of $\mathrm{Cu}$-NPs observed in the periplasm and cytoplasm: i) $\mathrm{Cu}$ (II) ions were able to enter the periplasm and cytoplasm where an, as yet, unidentified reductase/s reduced and precipitated the $\mathrm{Cu}-\mathrm{NPs}$; ii) reduction of $\mathrm{Cu}(\mathrm{II})$ and precipitation of the $\mathrm{Cu}-\mathrm{NPs}$ in the periplasm or cytoplasm followed by transport of the reduced NPs across the cytoplasmic membrane, possibly facilitated by membrane damage caused by $\mathrm{Cu}$ toxicity; iii) reduction of $\mathrm{Cu}(\mathrm{II})$ to $\mathrm{Cu}(\mathrm{I})$ in the cytoplasm followed by $\mathrm{Cu}(\mathrm{I})$ export and subsequent disproportionation to form $\mathrm{Cu}(0)$ and $\mathrm{Cu}(\mathrm{II})$. The later was suggested by Hofacker et al and Weber et al as the mechanism responsible for $\mathrm{Cu}(0)$ formation by bacteria under soil reducing conditions ${ }^{42-43}$. However, they were unable to replicate $\mathrm{Cu}(0)$ formation in cell suspensions of Clostridium species implicated in this study.

\section{Conclusions}

This study demonstrates the ability of $S$. oneidensis to facilitate the bioreduction of $\mathrm{Cu}$ (II) to form well-dispersed, biomass supported $\mathrm{Cu}(0)$ nanoparticles under environmentally benign conditions. Deletion mutants indicate that the Mtr pathway does not play an important role in 
the reduction process and suggests a novel reductase/s may be involved. Detailed characterization reveals the majority of nanoparticles are located within the periplasm and cytoplasm, further suggesting that bioreduction is an intracellular process. The nanoparticles remain stable against oxidation under anaerobic conditions, however, EELS spectra and atomic resolution high-angle annular dark field (HAADF) STEM images suggest that, when exposed to air, a partially oxidized $\mathrm{Cu}_{2} \mathrm{O}$ thin shell develops. The $\mathrm{Cu}-\mathrm{NPs}$ display good catalytic activity towards copper catalyzed azide-alkyne cycloaddition demonstrating a simple and green synthesis method for producing reactive $\mathrm{Cu}$ nanocatalysts. The possibility of targeting $\mathrm{Cu}(\mathrm{II})$ in wastewaters via bioreduction offers the potential to revalorize a range of industrial effluents e.g. from mining activities, adding an extra financial incentive to evaluate this emerging technology.

\section{Experimental}

Shewanella oneidensis: All cultures of S. oneidensis were grown anaerobically in a fully defined, pre-sterilized, liquid minimal medium ( $\mathrm{pH}$ 7.4) based on that described previously

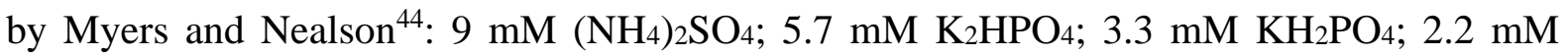
$\mathrm{NaHCO}_{3} ; 1 \mathrm{mM} \mathrm{MgSO} \cdot 7 \mathrm{H}_{2} \mathrm{O} ; 0.49 \mathrm{mM} \mathrm{CaCl} 2 \cdot 2 \mathrm{H}_{2} \mathrm{O} ; 67.2 \mu \mathrm{M} \mathrm{Na} 2 \mathrm{EDTA} ; 56.6 \mu \mathrm{M} \mathrm{H}_{3} \mathrm{BO}_{3}$; $10 \mu \mathrm{M} \mathrm{NaCl} ; 5.4 \mu \mathrm{M} \mathrm{FeSO} \cdot 7 \cdot 7 \mathrm{H}_{2} \mathrm{O} ; 5 \mu \mathrm{M} \mathrm{CoCl} 2 \cdot 6 \mathrm{H}_{2} \mathrm{O} ; 5 \mu \mathrm{M} \mathrm{NiCl} \cdot 6 \mathrm{H}_{2} \mathrm{O} ; 3.9 \mu \mathrm{M}$ $\mathrm{Na}_{2} \mathrm{MoO}_{4} \cdot 2 \mathrm{H}_{2} \mathrm{O} ; 1.5 \mu \mathrm{M} \mathrm{Na} 2 \mathrm{SeO}_{4} ; 1.3 \mu \mathrm{M} \mathrm{MnCO} ; 1 \mu \mathrm{M} \mathrm{ZnCl}_{2} ; 0.2 \mu \mathrm{M} \mathrm{CuSO} \cdot 5 \mathrm{H}_{2} \mathrm{O} ; 20$ $\mathrm{mg} \mathrm{L}^{-1} \mathrm{~L}$-arginine $\mathrm{HCl} ; 20 \mathrm{mg} \mathrm{L}{ }^{-1} \mathrm{~L}$-glutamate; $20 \mathrm{mg} \mathrm{L} \mathrm{L}^{-1} \mathrm{~L}$-serine; $100 \mathrm{mM}$ sodium DLlactate (carbon source and electron donor); $20 \mathrm{mM}$ fumarate (electron acceptor). Serum bottles $(100 \mathrm{ml})$ containing the defined medium were flushed with an 80:20 gas mix of $\mathrm{N}_{2}: \mathrm{CO}_{2}$ for 20 minutes to remove $\mathrm{O}_{2}$ and then sealed and autoclaved to sterilize the medium. After cooling, the medium was inoculated with a late log/early stationary phase culture to 
give an optical density of 0.02 at $600 \mathrm{~nm}$. The cultures were grown for 24 hours at $30^{\circ} \mathrm{C}$. The fully grown cultures were transferred anaerobically to centrifuge tubes, and the cells pelleted by centrifugation at $4,960 \mathrm{rpm}$ for 20 minutes at $4^{\circ} \mathrm{C}$. The cells were washed two times with fresh anoxic, sterilized MOPS buffer and then were resuspended in the same buffer at $\mathrm{pH}$ 7.1.

Cytochrome-deletion mutants: The c-type cytochrome deletion mutant JG596 lacks the outer membrane cytochromes MtrC, MtrF and OmcA ${ }^{45}$ where as JG1453 lacks the all the important cytochromes beyond the cytoplasmic membrane-bound tetrahaem c-type cytochrome CymA, namely: MtrABCDEF, OmcA, DmsE, S04360, CctA. ${ }^{46}$ The mutants were cultured as described above for the MR-1 wild type strain. Both mutant strains were kindly provided by Jeff Gralnick (University of Minnesota).

Copper bioreduction: The kinetics and extent of copper reduction by S. oneidensis MR-1 wild type and mutants was determined using a standard resting cell experiment. The copper reduction assay contained either $50 \mu \mathrm{M}$ or $200 \mu \mathrm{M} \mathrm{Cu(II)}$ as $\mathrm{CuSO}_{4}$ and $30 \mathrm{mM}$ sodium lactate as the electron donor in $50 \mathrm{mM}$ MOPS adjusted to $\mathrm{pH} 7.1$. The medium was purged with an 80:20 gas mix of $\mathrm{N}_{2}: \mathrm{CO}_{2}$ for 20 minutes to remove $\mathrm{O}_{2}$, sealed with thick butyl rubber stoppers and autoclaved. Late log/early stationary phase cells were washed and harvested and then added aseptically to achieve a final optical density of 0.1 and incubation was carried out at $20^{\circ} \mathrm{C}$. Soluble $\mathrm{Cu}(\mathrm{II})$ was determined by taking aliquots and centrifuging at $14,900 \mathrm{RPM}$ for 10 minutes to pellet the cells and insoluble copper. Samples were taken from the supernatant and $\mathrm{Cu}(\mathrm{II})$ in solution measured using ICP-AES. 
Serial block-face scanning electron microscopy (3View): $1 \mathrm{ml}$ suspensions of wild type $S$. oneidensis $\mathrm{MR}-1$ challenged with $50 \mu \mathrm{M} \mathrm{Cu}$ (II) (with $30 \mathrm{mM}$ lactate as the electron donor) were taken and centrifuged at 14,900 RPM for 10 minutes. The supernatant was discarded and the cells were resuspended and washed in anoxic deionized water. The cell suspension was centrifuged again, the resulting pellet was fixed in $2.5 \%$ glutaraldehyde, $4 \%$ Paraformaldehyde in 0.1M HEPES ( $\mathrm{pH}$ 7.2) for one hour at room temperature. Following the initial fixation the pellet was resuspended in $1.5 \%$ low melting point agarose, spun down and set on ice. The pellet was cut to size and fixed in primary fix for a further hour at room temperature. Following this it was treated as a solid tissue sample and taken for a standard TEM preparation. Briefly, it was washed 3 times in deionized water for 5 minutes on a rotary shaker. Reduced osmium ( $1 \%$ osmium with $0.75 \%$ potassium ferrocyanide in $0.1 \mathrm{M}$ Sodium cacodylate buffer $\mathrm{pH}$ 7.2) was added as a secondary fix/stain and the pellet was then washed 5 times as before. Uranyl acetate was added as a further stain before another 2 washes were performed. The pellet was then dehydrated for 15 minutes in increasing ethanol solutions (30, $50,70,90,100 \%)$ before being washed twice in acetone for 30 minutes. The resin was infiltrated using increasing concentrations $(25,50,75,100 \%)$ with each infiltration alternating over night or over a day. Finally, the pellet was put into molds with fresh resin and set in an oven at $60^{\circ} \mathrm{C}$ for 2 days. Serial block face image stacks were collected using a Gatan 3view mounted in an FEI Quanta 250FEG. The microscope was run at 0.3 Torr, $3.8 \mathrm{kV}$. Images (4096x4096) were collected with $5.58 \mathrm{~nm}$ pixels, with a $1 \mu \mathrm{s}$ dwell time with slices cut at $50 \mathrm{~nm}$.

TEM and STEM imaging and EELS of whole mount samples: Whole mount TEM samples of cultures of the wild type MR-1 and mutants were prepared in an anaerobic chamber using 
anoxic solutions. $1 \mathrm{ml}$ of cell suspensions of $S$. oneidensis MR-1 challenged with $50 \mu \mathrm{M}$ $\mathrm{Cu}$ (II) (with $30 \mathrm{mM}$ sodium lactate) were taken after 24 hours and centrifuged at 14,900 RPM for 5 minutes, the supernatant discarded and the pellet resuspended in $1 \mathrm{ml}$ deionized water. $1.5 \mu \mathrm{l}$ of the cell suspension was pipetted onto a gold TEM grid with a holey-carbon or carbon-coated formvar support film and allowed to air dry in an anaerobic chamber. Samples were kept anaerobic until they were transferred into the TEM chamber, during which they would have been very briefly exposed to the atmosphere. TEM imaging and EDX analysis were performed in an FEI Tecnai F30 FEG Analytical TEM operated at $300 \mathrm{kV}$. EDX analysis was performed with the sample tilted at the optimum angle towards the detector to increase collection efficiency.

STEM imaging, EDX analysis, and EELS of whole mount samples were performed in a probe side aberration-corrected FEI Titan G2 with an X-FEG electron source operated at 200 $\mathrm{kV}$. High angle annular dark field (HAADF) STEM imaging was performed using a probe convergence angle of $21 \mathrm{mrad}$, a HAADF inner angle of $54 \mathrm{mrad}$, and a probe current of approximately 180 pA. EELS was performed using a Gatan Imaging Filter (GIF) Quantum ER system with a $5 \mathrm{~mm}$ entrance aperture, a collection angle of $62 \mathrm{mrad}$ and an energy dispersion of $1 \mathrm{eV}$. EDX analysis was performed using a Super-X four silicon drift EDX detector system with a total collection solid angle of $0.7 \mathrm{srad}$, all four detectors were turned on and the sample was not tilted.

TEM and STEM imaging of thin section samples: Cross-section TEM and STEM samples of cultures of the MR-1 wild type strain were prepared from the 3view pins. Sections (50-70 nm) were cut with a diamond knife on a Reichert-Jung Ultracut. The sections were collected onto holey-carbon supported gold TEM grids. Thin section TEM and EDX analysis were 
performed in an FEI Tecnai F30 FEG Analytical TEM operated at 300kV as described above. Thin section STEM and EDX analysis were performed using an Oxford Instruments X-Max silicon drift EDX detector system with data collection and analysis performed using Oxford Instruments Aztec software suite.

$X$-ray absorption spectroscopy (XAS) characterization: For XAS characterization at the $\mathrm{Cu}$ $K$-edge, $1 \mathrm{ml}$ aliquots of $S$. oneidensis MR-1 challenged with $50 \mu \mathrm{M} \mathrm{Cu}(\mathrm{II})$ (with $30 \mathrm{mM}$ lactate) were taken and centrifuged (14,900 RPM for 5 minutes), the supernatant discarded and the pellet resuspended in $1 \mathrm{ml}$ anoxic deionized water. $200 \mu \mathrm{l}$ of the suspension was pipetted onto a plastic weighing boat and air dried overnight. All manipulations were performed inside an anaerobic chamber. Samples were mounted onto a layer of kapton tape which in turn was mounted onto an aluminum sample holder. A further layer of kapton tape was applied over the samples to maintain anaerobicity. EXAFS spectra were collected at room temperature at the $\mathrm{Cu} K$-edge $(\sim 8980 \mathrm{eV})$ on beamline B18 at the Diamond Light Source. A 36-element solid-state Ge detector with digital signal processing for fluorescence EXAFS, high energy resolution, and high count rate was used to measure with the beam at $45^{\circ}$ incidence with respect to the sample holder plane. All spectra were acquired in quickEXAFS mode, using the Pt-coated branch of collimating and focusing mirrors, a $\mathrm{Si}(111)$ double-crystal monochromator and a pair of harmonic rejection mirrors.

For XAS characterization at the $\mathrm{Cu} L_{2,3}$-edges, samples were washed as above and then pipetted onto carbon tape mounted on an aluminum sample holder which was sealed in an air-tight coffin to maintain anaerobicity. The samples were loaded into the portable octupole magnet system (POMS) on beamline I10 at Diamond Light Source, under a backflow of nitrogen and then held in a vacuum for the duration of the measurement. The XAS spectra 
were recorded simultaneously using the total electron yield (TEY) and fluorescence yield (FY) detection at room temperature at the $\mathrm{Cu} L_{2,3}$-edges.

XANES processing was carried out using Athena while EXAFS data were modelled using Artemis (Demeter; 0.9.24) ${ }^{47}$ Fitting was calculated using multiple k-weights (k1, k2, and k3) and the best fit was calculated in $\mathrm{R}$ space by minimization of the reduced $\mathrm{X}^{2}$. At no point did parameterization of the EXAFS model use more than $2 / 3$ of the total number of available independent points.

Synthesis of triazole derivatives: Benzyl azide $1(0.25 \mathrm{mmol}, 37 \mathrm{mg})$, the suitable alkyne 2a-c (0.25 mmol, 21-33 mg) and $\mathrm{Et}_{3} \mathrm{~N}(0.25 \mathrm{mmol}, 25 \mathrm{mg})$ were dissolved in $\mathrm{H}_{2} \mathrm{O} / \mathrm{t}-\mathrm{BuOH}(5.0$ $\mathrm{mL}, 8: 2)$. Following bioreduction of $\mathrm{Cu}(\mathrm{II})(50 \mu \mathrm{M})$, suspension of $\mathrm{S}$. oneidensis cells with associated $\mathrm{Cu}-\mathrm{NPs}$ were washed 3 times and then resuspended in deionized water. An aliquot of the suspension $(500 \mu \mathrm{L}$, equivalent to $1.1 \mathrm{~mol} \% \mathrm{Cu})$, was added to the solution and the mixture was stirred at room temperature for $12 \mathrm{~h}$. The mixture was extracted with EtOAc $(3 \times$ $10 \mathrm{~mL})$, then the combined organic phase was washed with brine $(20 \mathrm{~mL})$, dried over anhydrous $\mathrm{MgSO}_{4}$ and evaporated under reduced pressure. The crude product 3a-c (of sufficient purity for further chemical transformations) was purified either by recrystallization $\left(\mathrm{EtOH} / \mathrm{H}_{2} \mathrm{O}\right)$ or by column chromatography on silica (n-Hex/EtOAc 8:2). Full characterization of the products is reported in the Supporting Information.

\section{Supporting Information}

Supporting Information is available from the Wiley Online Library 


\section{Acknowledgements}

We would like to thank NERC for funding under the Resource Recovery from Waste program (NE/L014203/1). We would also like to thank J Gralnick (University of Minnesota) for kindly supplying the deletion mutant strains and P Lythgoe (University of Manchester) for ICP-AES analysis. K Smith would like to acknowledge EnviroRadNet for funding. We acknowledge beamtime awarded at the Diamond Light Source for XAS on beamline I10 under proposal SI-15476 and for XANES and EXAFS on beamline B18 under proposal SP16136.

\section{Conflict of Interest}

The authors declare no conflict of interest

\section{References}

1. M. B. Gawande, A. Goswami, F. X. Felpin, T. Asefa, X. Huang, R. Silva, X. Zou, R. Zboril, R. S. Varma, Chem. Rev. 2016, 116, 3722.

2. V. V. Rostovtsev, L. G. Green, V. V. Fokin, K. B. Sharpless, Angew. Chem. Int. Ed. 2002, 41, 2596.

3. C. W. Tornøe, C. Christensen, M. Meldal, J. Org. Chem. 2002, 67, 3057.

4. S. G. Agalave, S. R. Maujan, V. S. Pore, Chem. Asian. J. 2011, 6, 2696.

5. H. C. Kolb, K. B. Sharpless, Drug Discovery Today 2003, 8, 1128.

6. K. B. Sharpless, R. Manetsch, Expert Opin. Drug. Discov. 2006, 1, 525.

7. T. Zheng, S. H. Rouhanifard, A. S. Jalloh, P. Wu, Top. Heterocycl. Chem. 2012, 28, 163. 
8. J. E. Moses, A. D. Moorhouse, Chem. Soc. Rev. 2007, 36, 1249.

9. R. Breinbauer, M. Köhn, ChemBioChem 2003, 4, 1147.

10. W. Xi, T. F. Scott, C. J. Kloxin, C. N. Bowman, Adv. Funct. Mater. 2014, 24, 2572.

11. R. Kortlever, J. Shen, K. J. P. Schouten, F. Calle-Vallejo, M. T. M. Koper, J. Phys. Chem. Lett. 2015, 6, 4073.

12. A. T. Bell, Science 2003, 299, 1688.

13. T. Jin, M. Yan, Y. Yamamoto, ChemCatChem 2012, 4, 1217.

14. R. Hudson, C. J. Li, A. Moores, Green Chem. 2012, 14, 622.

15. J. R. Lloyd, J. M. Byrne, V. S. Coker, Curr. Opin. Biotechnol. 2011, 22, 509.

16. K. B. Narayanan, N. Sakthivel, Adv. Colloid Interface Sci. 2010, 156, 1.

17. J. M. Byrne, H. Muhamadali, V. S. Coker, J. Cooper, J. R. Lloyd, J. R. Soc. 2015, 12.

18. J. M. Byrne, N. D. Telling, V. S. Coker, R. A. Pattrick, G. van der Laan, E. Arenholz, F. Tuna, J. R. Lloyd, Nanotechnology 2011, 22, 455709.

19. J. R. Lloyd, FEMS Microbiol. Rev. 2003, 27, 411.

20. M. J. Marshall, A. S. Beliaev, A. C. Dohnalkova, D. W. Kennedy, L. Shi, Z. Wang, M. I. Boyanov, B. Lai, K. M. Kemner, J. S. McLean, S. B. Reed, D. E. Culley, V. L. Bailey, C. J. Simonson, D. A. Saffarini, M. F. Romine, J. M. Zachara, J. K. Fredrickson, PLoS Biol. 2006, 4 , e268.

21. C. I. Pearce, R. A. D. Pattrick, N. Law, J. M. Charnock, V. S. Coker, J. W. Fellowes, R. S. Oremland, J. R. Lloyd, Environ. Technol. 2009, 30, 1313.

22. W. D. Windt, P. Aelterman, W. Verstraete, Environ. Microbiol. 2005, 7, 314.

23. A. K. Suresh, D. A. Pelletier, W. Wang, M. L. Broich, J. W. Moon, B. Gu, D. P. Allison, D. C. Joy, T. J. Phelps, M. J. Doktycz, Acta Biomater. 2011, 7, 2148. 
24. R. Ramanathan, M. R. Field, A. P. O'Mullane, P. M. Smooker, S. K. Bhargava, V. Bansal, Nanoscale 2013, 5, 2300.

25. I. K. Suh, H. Ohta, Y. Waseda, J. Mater. Sci. 1988, 23, 757.

26. N. S. Marinković, K. Sasaki, R. R. Adžić, Zaštita materijala 2016, 57, 101.

27. M. Mansour, L. Favergeon, M. Pijolat, Thermochim. Acta 2013, 570, 41.

28. B. J. Borah, D. Dutta, P. P. Saikia, N. C. Barua, D. K. Dutta, Green Chem. 2011, 13, 3453.

29. F. Himo, T. Lovell, R. Hilgraf, V. V. Rostovtsev, L. Noodleman, K. B. Sharpless, V. V. Fokin, J. Am. Chem. Soc. 2005, 127, 210.

30. M. R. Decan, S. Impellizzeri, M. L. Marin, J. C. Scaiano, Nat. Commun. 2014, 5, 4612.

31. F. Alonso, Y. Moglie, G. Radivoy, Acc. Chem. Res. 2015, 48, 2516.

32. L. Shi, T. C. Squier, J. M. Zachara, J. K. Fredrickson, Mol. Microbiol. 2007, 65, 12.

33. Y. Xiong, L. Shi, B. Chen, M. U. Mayer, B. H. Lower, Y. Londer, S. Bose, M. F. Hochella, J. K. Fredrickson, T. C. Squier, J. Am. Chem. Soc. 2006, 128, 13978.

34. J. K. Fredrickson, J. M. Zachara, Geobiology 2008, 6, 245.

35. M. J. Marshall, A. E. Plymale, D. W. Kennedy, L. Shi, Z. Wang, S. B. Reed, A. C. Dohnalkova, C. J. Simonson, C. Liu, D. A. Saffarini, M. F. Romine, J. M. Zachara, A. S. Beliaev, J. K. Fredrickson, Environ. Microbiol. 2008, 10, 125.

36. J. M. Myers, W. E. Antholine, C. R. Myers, Appl. Environ. Microbiol. 2004, 70, 1405.

37. C. K. Ng, T. K. Cai Tan, H. Song, B. Cao, RSC Adv. 2013, 3, 22498.

38. D. B. Li, Y. Y. Cheng, C. Wu, W. W. Li, N. Li, Z. C. Yang, Z. H. Tong, H.-Q. Yu, Sci. Rep. 2014, 4, 3735. 
39. L. Rodríguez-Montelongo, S. I. Volentini, R. N. Farías, E. M. Massa, V. A. Rapisarda, Arch. Biochem. Biophys. 2006, 451, 1.

40. S. Tottey, D. R. Harvie, N. J. Robinson, Acc. Chem. Res. 2005, 38, 775.

41. A. C. Toes, M. H. Daleke, J. G. Kuenen, G. Muyzer, Microbiology 2008, 154, 2709.

42. A. F. Hofacker, S. Behrens, A. Voegelin, R. Kaegi, T. Lösekann-Behrens, A. Kappler, R. Kretzschmar, Geomicrobiol. J. 2015, 32, 130.

43. F. A. Weber, A. Voegelin, R. Kaegi, R. Kretzschmar, Nat. Geosci. 2009, 2, 267.

44. C. R. Myers, K. H. Nealson, Science 1988, 240, 1319.

45. D. Coursolle, J. A. Gralnick, Mol. Microbiol. 2010, 77, 995.

46. D. Coursolle, J. A. Gralnick, Front. Microbiol. 2012, 3, 56.

47. B. Ravel, M. Newville, Phys. Scr. 2005, 2005, 1007. 


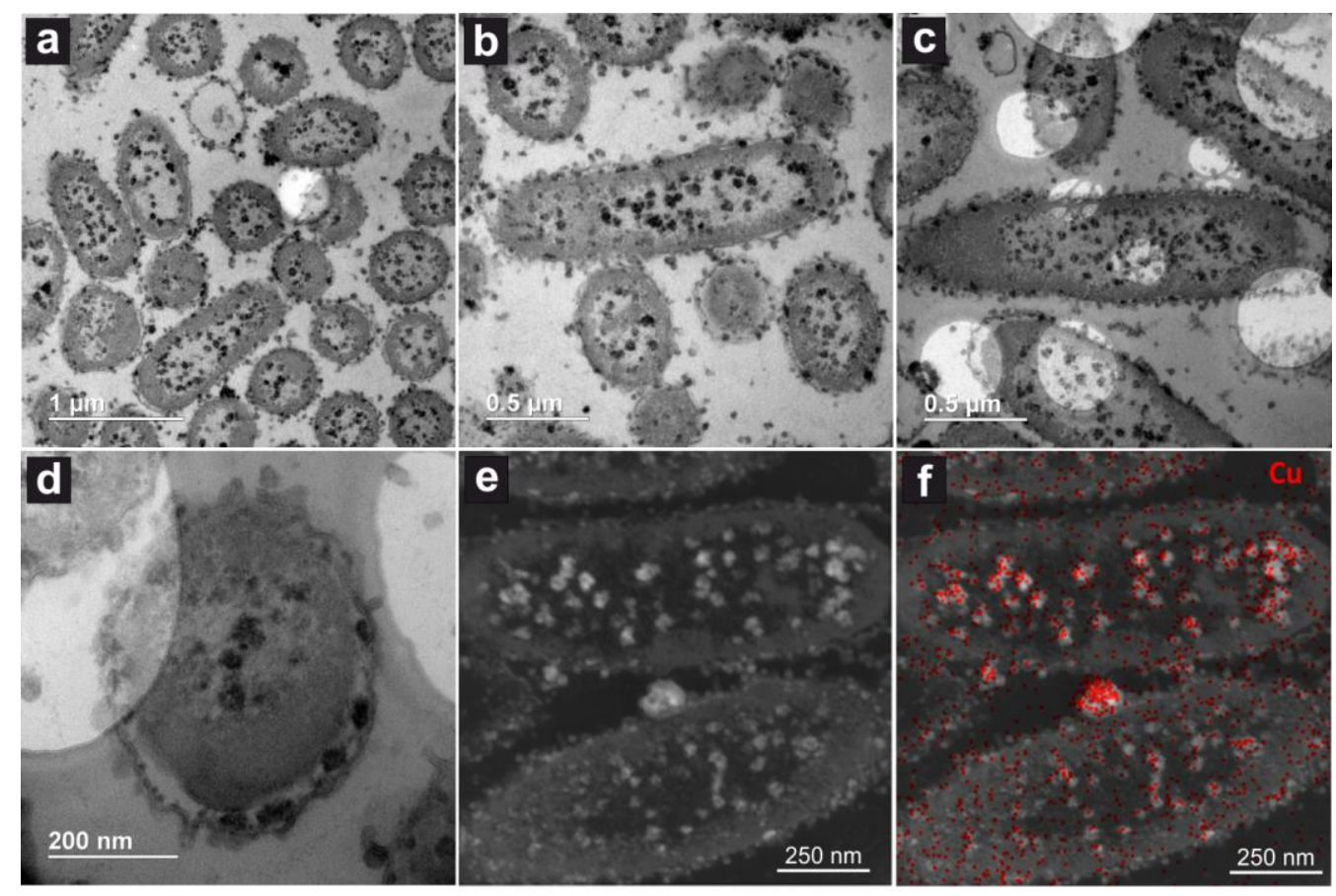

Figure 1. (a-d) Thin section TEM images of Shewanella oneidensis MR-1 and copper nanoparticles. (e) High-angle annular dark field (HAADF) image and (f) Cu EDX map performed at the $\mathrm{Cu} \mathrm{K} \alpha$ peak. 

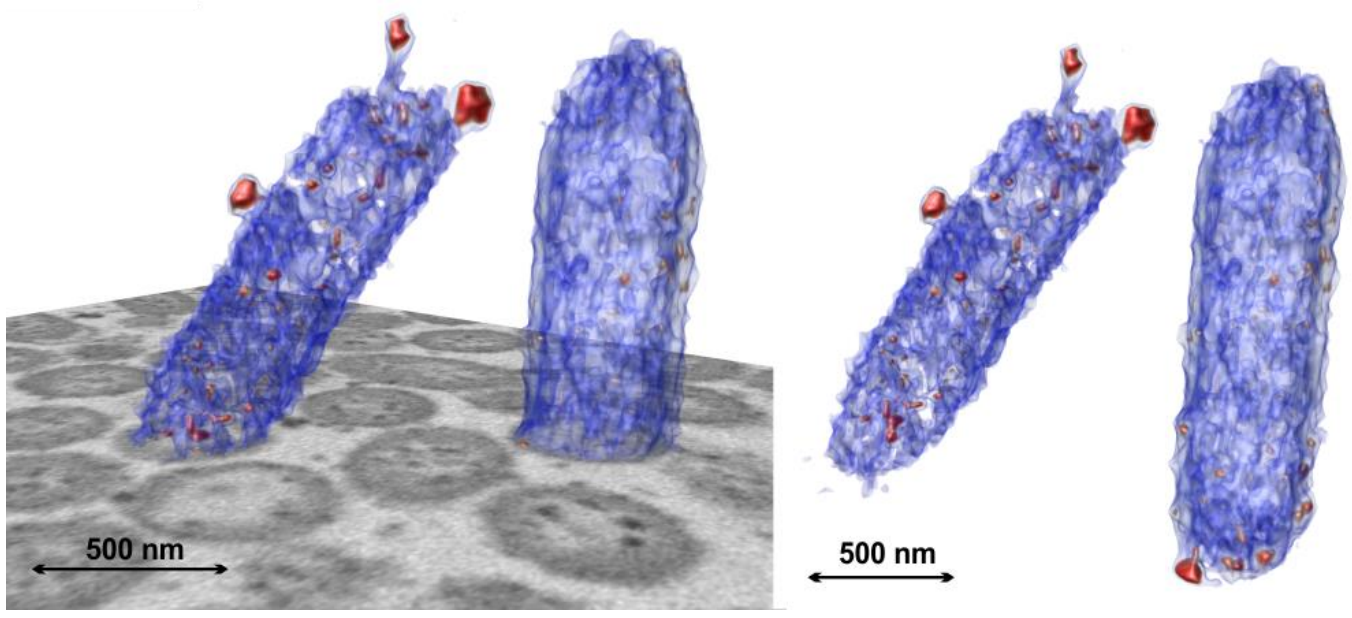

Figure 2. Reconstructed '3D' SBFSEM image showing the dispersion of copper nanoparticles in cells of Shewanella oneidensis MR-1. The blue color is applied to the 'light' low atomic weight elements of each scan and represents the cellular structure. The red is applied to the 'dark' heavier elements of the SEM scans and represents the Cu nanoparticle component. 
(a)

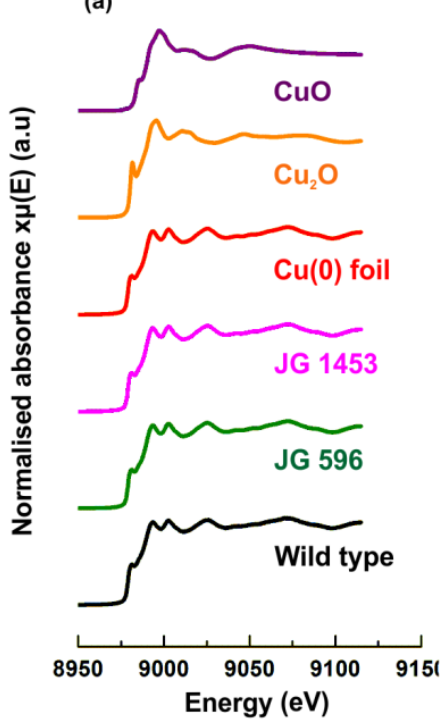

(b)

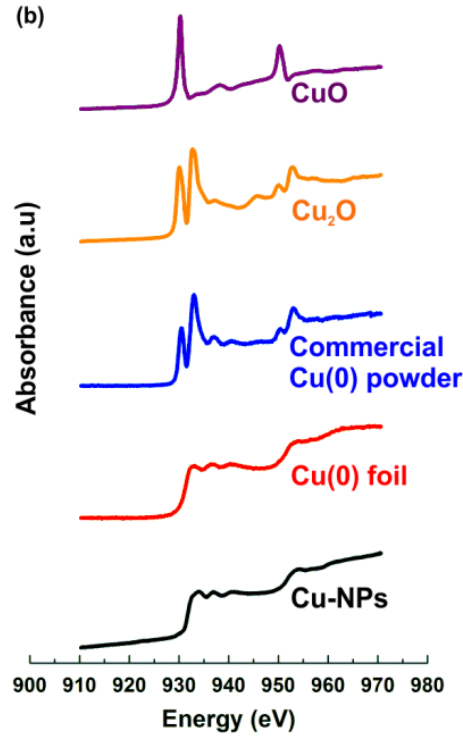

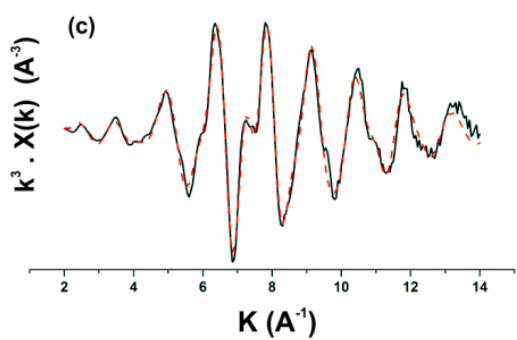

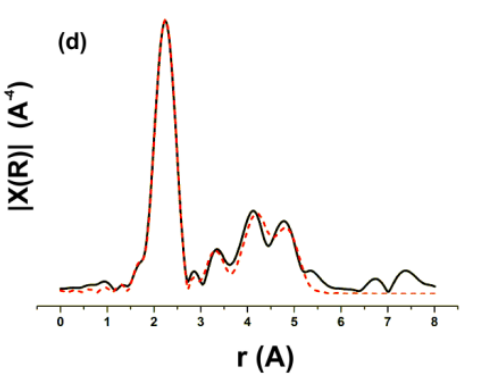

Figure 3. (a) XANES for the $\mathrm{Cu}$ K-edge of $\mathrm{Cu}$-NPs produced by cells of $S$. oneidensis $\mathrm{MR}-1$ (wild type) and cytochrome deletion mutants and (b) $\mathrm{Cu} L_{2,3}$-edge of the Cu-NPs produced by the wild type. (c) EXAFS and (d) corresponding Fourier Transform for the $\mathrm{Cu} K$-edge of the Cu-NPs. Data are shown by the black (solid) line and the fit is shown by the red (dotted) line. 

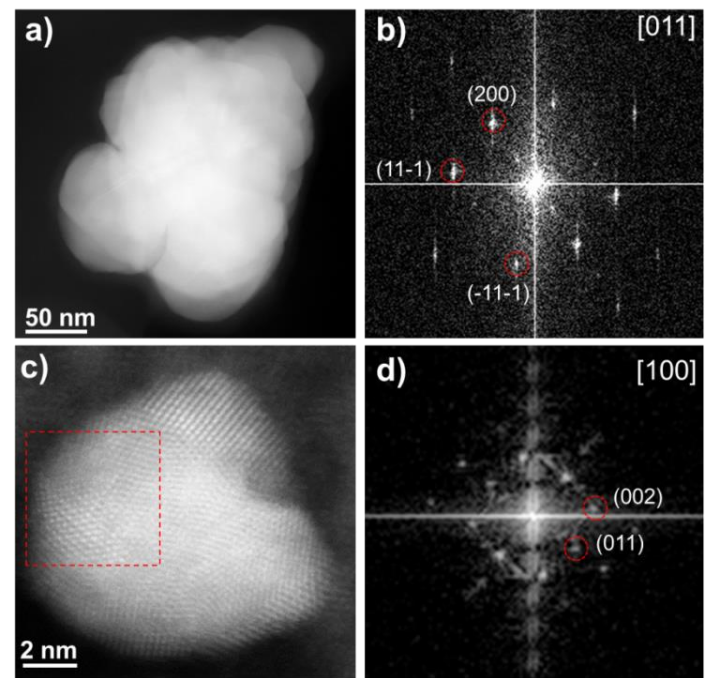

Figure 4. (a) Lattice resolution HAADF STEM image of agglomerated biogenic copper nanoparticles with (b) corresponding Fourier transform (FT). The FT indexes to $\mathrm{Cu}(0)$ viewed down the [011] size axis. (c) Atomic resolution HAADF STEM image of small nanocrystal ( $10 \mathrm{~nm}$ diameter), the FT taken from the region indicated by the dashed box in (c) is shown in (d) and indexes to $\mathrm{Cu}_{2} \mathrm{O}$ viewed down the [100] zone axis. 

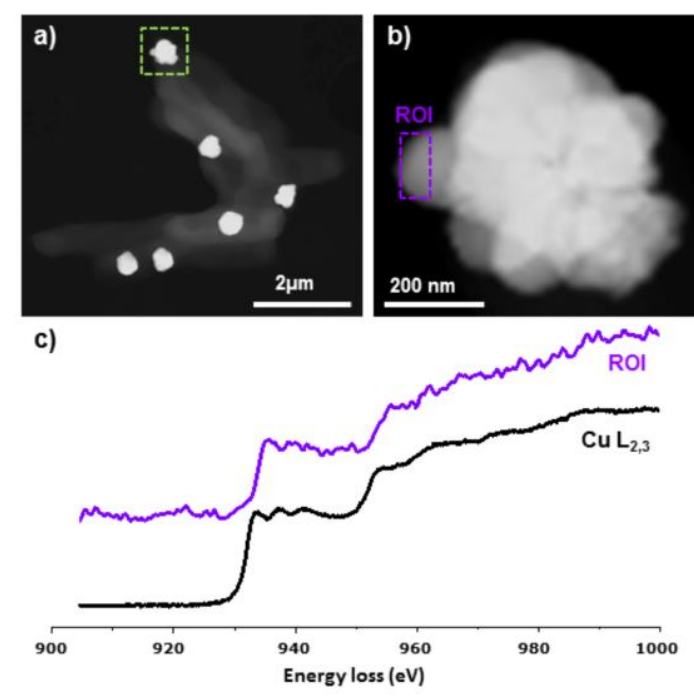
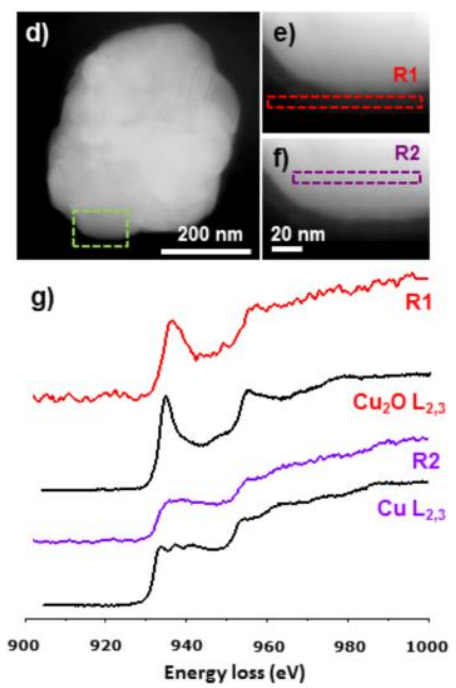

Figure 5. (a) HAADF image of cells of $S$. oneidensis MR-1 and Cu-NPs. Cu-NPs selected for EELS analysis are highlighted in the dashed (green) box in (a) and are shown in (b). (c) EELS spectrum of the region of interest (ROI) from image (b) (purple line) compared to reference spectrum of $\mathrm{Cu}$ metal (black line). (d) HAADF image of $\mathrm{Cu}-\mathrm{NPs}$; the region analyzed in (e) and (f) is indicated by a dashed (green) box in (d). (e) region of interest at edge of the particle (R1); (f) region of interest representing the bulk particle (R2); (g) corresponding EELS spectra from the two regions of interests highlighted in images (e) (red line) and (f) (purple line) compared to reference spectra of $\mathrm{Cu}_{2} \mathrm{O}$ and $\mathrm{Cu}$ metal (black lines). 


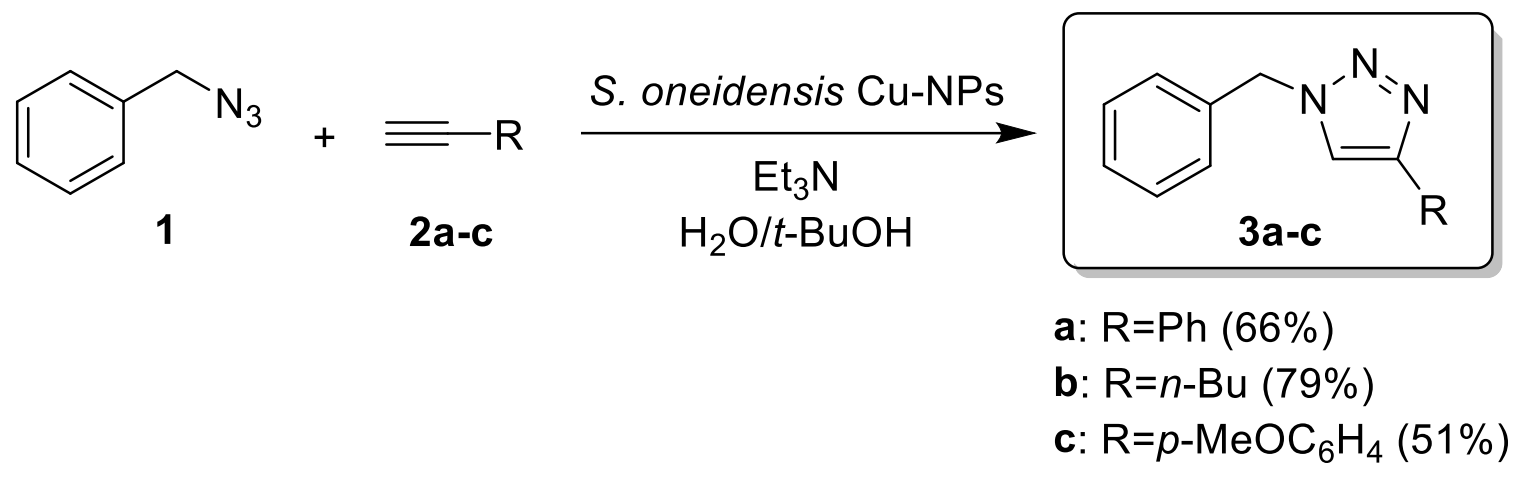

Scheme 1. Synthesis of substituted triazoles mediated by S. oneidensis Cu-NPs. 
A novel green biosynthesis route for the production of functional copper nanoparticles $(\mathrm{Cu}-$ NPs) using a metal-reducing bacterium is reported. Detailed characterization reveals welldispersed $\mathrm{Cu}(0)$ nanoparticles with a thin, stable $\mathrm{Cu}_{2} \mathrm{O}$ surface layer. The catalytic activity of the biogenic $\mathrm{Cu}-\mathrm{NPs}$ was demonstrated for a range of 'click chemistry' azide-alkyne cycloaddition reactions.

Keyword: copper nanoparticles; biosynthesis; click chemistry; Shewanella oneidensis; XANES

Richard L. Kimber*, Edward A. Lewis, Fabio Parmeggiani, Kurt Smith, Heath Bagshaw, Toby Starborg, Nimisha Joshi, Adriana I. Figueroa, Gerrit van der Laan, Giannantonio Cibin, Diego Gianolio, Sarah J. Haigh, Richard A.D. Pattrick, Nicholas J. Turner, Jonathan R. Lloyd

Title: Biosynthesis and Characterization of Copper Nanoparticles Using Shewanella oneidensis: Application for Click Chemistry

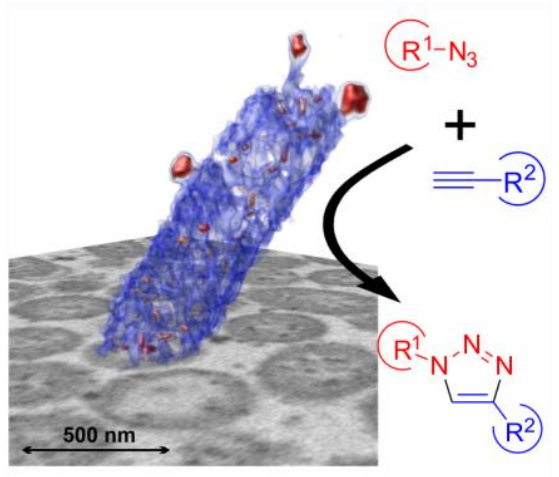

